\title{
Tierra del Fuego: construcción científico-política de la exclusión y contraimagen del ideal citadino
}

\author{
Gabriela Nacach (*) \\ $\left(^{*}\right) \quad$ Instituto de Ciencias Antropológicas. Facultad de Filosofía y Letras. Universidad de Buenos \\ Aires.gabicolombina@yahoo.com.ar
}

Dynamis

[0211-9536] 2012; $32(1): 69-92$
Fecha de recepción: 5 de abril de 2011

Fecha de aceptación: 10 de octubre de 2011

SUMARIO: 1.-Hacer vivir al delincuente. Dejar morir al indio. 2.-Las agencias estatal y salesiana en la colonización del indio. 3.-La colonización bioantropológica. 3.1.-Taxonomización y registro. 3.2.-Paradigma de la extinción. 4.-El penal de Ushuaia: ¿contraimagen citadina o contracara del ideal de normalidad de la nación? 4.1.-Colonización penal. 4.1.1.—Los criminales: los sujetos del progreso del territorio. 4.1.2.-Un gabinete de control y observación. 5.-Conclusiones.

RESUMEN: En su incorporación al Estado nacional argentino, Tierra del Fuego se caracterizó por un contexto socio-económico y político distintivo del resto del territorio nacional. Más tardía que en el resto de la República, la colonización de la región austral se sitúa en la última década del siglo XIX y primeros años del siglo XX, fechas que coinciden con el establecimiento del penal de Ushuaia (construido paulatinamente desde 1886; emplazado definitivamente en 1896), las misiones salesianas del lado argentino y chileno de la isla (1893 y 1888 respectivamente), y la instalación de los grandes latifundios. En la construcción de alteridades subalternas, se impondrán objetivaciones y representaciones en las cuales intervendrán instancias o agencias (estatales y no estatales). La misión salesiana de La Candelaria y la Cárcel de Reincidentes de Ushuaia se destacan en este devenir como espacios de concreción de la biopolítica. Indígenas fueguinos y criminales serán el elemento a someter. La tesis de la extinción del indio, y la simultánea exaltación del criminal como sujetos del progreso, identificarán los mecanismos político-científicos por medio de los cuales se regulará un proceso tendiente a excluir a determinados colectivos sociales de la nacionalidad (indígenas fueguinos) e incluir otros (delincuentes).

PALABRAS CLAVE: Tierra del Fuego, siglos XIX y XX, biopolítica, paradigmas, colonización.

KEY WORDS: Tierra del Fuego, 19th and 20th centuries, biopolitics, paradigms, colonization. 


\section{Hacer vivir al delincuente. Dejar morir al indio}

En el Territorio de Tierra del Fuego - el más austral de la República Argentina-, la colonización y las formas en que se llevaron adelante las leyes en materia territorial, se caracterizaron por su disimilitud con las regiones de la Pampa y la Patagonia Norte. Más tardía que en el resto de la República, la colonización de la región austral se sitúa en la última década del siglo XIX y primeros años del siglo XX, fechas que coinciden con el establecimiento del penal de Ushuaia (construido paulatinamente desde 1886; emplazado definitivamente en 1896), las misiones salesianas del lado argentino y chileno de la isla (1893 y 1888 respectivamente), y la instalación de los grandes latifundios (Figura 1).

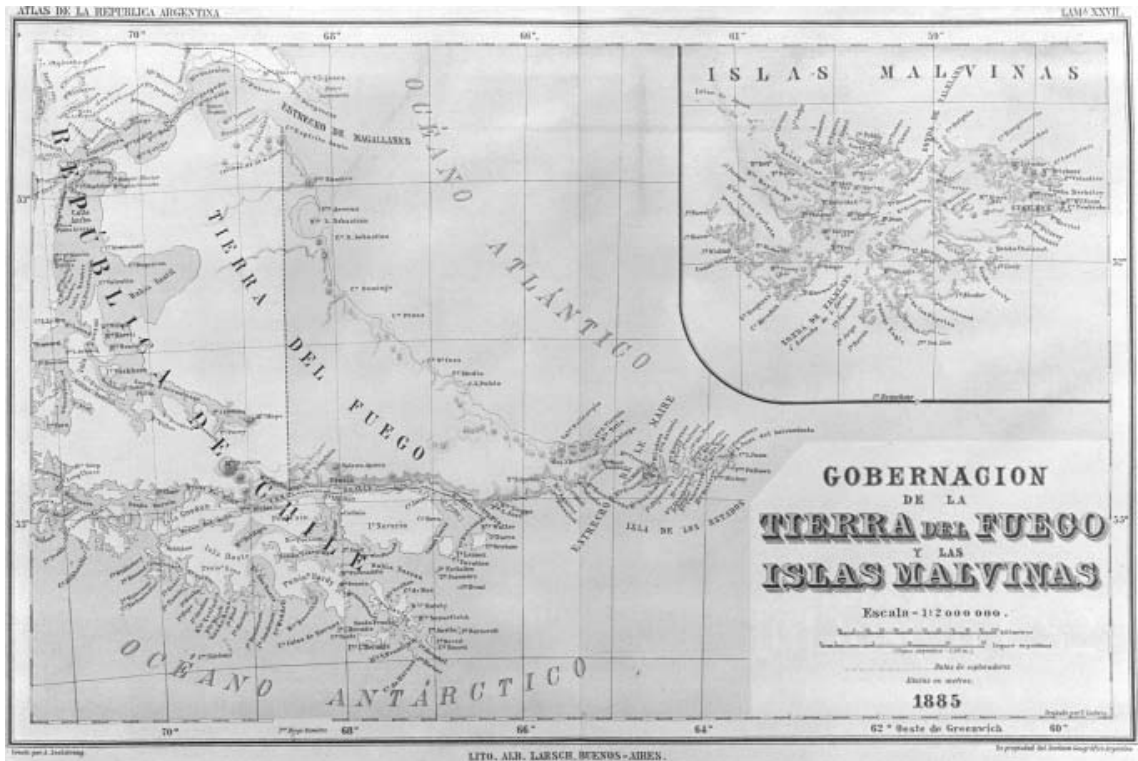

Figura 1.-Mapa de la Gobernación de Tierra del Fuego y las Islas Malvinas — sin la reducción salesiana y el penal de Ushuaia ya que no se hallaban instalados aún en la isla-. Confeccionado por Arturo Seelstrang en 1885 y publicado en 1886 bajo el auspicio del Gobierno Nacional. Fuente: Instituto Geográfico Militar de la República Argentina. 1886. Reproducido con autorización.

Las políticas derivadas de la interpretación de Darwin y la consiguiente adopción del paradigma evolucionista, se convirtieron en herramientas de 
exclusión y producción de subalternidad diferenciada ${ }^{1}$. En el contexto finisecular, las agencias estatal $-\mathrm{y}$ por su intermedio la ciencia- y salesiana se disputarán el control de los cuerpos en el territorio.

Para delimitar este proceso, adoptamos el concepto de biopolítica acuñado por Michel Foucault. Según el autor, la biopolítica se define como una tecnología de gobierno y regulación, ya no de sujetos individuales, sino de poblaciones. Un mecanismo que favorece «la emergencia de un tipo ideal deseado (como prototipo de normalidad) a contraluz y mediante la exclusión violenta de la "otredad" ${ }^{2}$.

El poder de soberanía, absoluto, dramático, sombrío - afirma Foucaultconsistente en poder hacer morir, introduce «la tecnología del biopoder, la tecnología del poder sobre la población como tal [...] un poder que yo llamaría de regulación y que consiste, al contrario, en hacer vivir y dejar morir» ${ }^{3}$. En otros términos, el biopoder permite hacer vivir a aquellos grupos que mejor se adaptaran al perfil de ciudadano anhelado por el Estado y dejar morir a aquellos otros que no permitieran el natural desenvolvimiento de la sociedad. En este contexto, el racismo va a desarrollarse no solamente para destruir al adversario político, «sino a la población rival, esa especie de peligro biológico que representan para la raza que somos, quienes están frente a nosotros» ${ }^{4}$. Indígenas y delincuentes formarán parte de esa población a destruir.

1. Hacemos alusión, específicamente, al uso político de las ideas vinculadas a la lucha por la vida, la supervivencia del más apto y de esta última, la inevitable extinción de las formas menos perfeccionadas expuestas por Charles Darwin en el año 1859 y 1871. Darwin, Charles. El origen de las especies. Buenos Aires: Planeta Agostini; 1985, 2 vols., y Darwin, Charles. The descendent of man. London: Penguin Books; 2004. El papel de la selección natural en la eliminación de los desviantes, y la alusión a una economía de la naturaleza donde la extinción aseguraba la policía de las poblaciones, son analizados por Girón Sierra, Álvaro. Darwinismo, darwinismo social e izquierda política (1859-1914). Reflexiones de carácter general. In: Miranda, Marisa; Vallejo, Gustavo, comps. Darwinismo social y eugenesia en el mundo latino. Buenos Aires: Siglo XXI; p. 23-58, cursivas en el original.

2. Castro-Gómez, S. Michael Foucault y la colonialidad del poder. Tabula Rasa. 2007; 6: 153-172. Disponible en: http://redalyc.uaemex.mx/pdf/396/39600607.pdf [citada 5 de Mar 2011].

3. Foucault, Michel. Defender la sociedad. Buenos Aires: FCE; 2000, p. 223. Cursivas en el original.

4. Foucault, n. 3, p. 232. El poder del soberano del Antiguo Régimen da paso, así, al poder disciplinar y el control social en la sociedad disciplinaria se constituirá a través de una red de dispositivos o aparatos de regulación. La puesta en marcha de esta sociedad aseguraría la obediencia a sus reglas por medio de las instituciones destinadas a estructurar el terreno de lo social y presentar lógicas adecuadas a la razón. Tecnología de poder difusa, capilar: «se trata en cierto modo de una microfísica del poder que los aparatos y las instituciones ponen en juego, pero cuyo campo de validez se sitúa en cierto modo entre esos grandes 
Sin embargo, su tratamiento será disímil. Por un lado, las políticas hacia los fueguinos cristalizan la relación de inmanencia entre la biopolítica y el racismo moderno de estado establecida por Foucault. Esto es, «la definición de otro-exterior racializado sobre el cual se podrían ejercitar las prácticas de exterminio en nombre del bienestar y seguridad de la población» ${ }^{5}$. Por el otro lado, la solución del problema criminal siguió otros cauces que los planteados por los cánones científicos de la época.

Este trabajo aborda dos cuestiones vinculadas a los espacios de concreción de la biopolítica, con el objetivo de identificar los mecanismos político-científicos por medio de los cuales se incluyen o excluyen determinados colectivos sociales a la nación. En primer lugar, se analizan las relaciones y disputas que se tejieron entre el Estado, el conocimiento científico y la agencia salesiana, bajo la figura de la misión Nuestra Señora de la Candelaria, en el marco del control de los cuerpos en el territorio. En segunda instancia y de forma paralela, las políticas de poblamiento de la isla, derivadas del acuciante problema demográfico, tendrán su correlato en la Cárcel de Reincidentes instalada en Ushuaia. Una vez resuelta la llamada cuestión del indio, el penal pondría freno a la escoria citadina al enviarla al confín del mundo, constituyéndose como la contraimagen de los criterios de normalidad emanados de las grandes metrópolis. Paradójicamente, los criminales serán considerados como los sujetos del progreso del territorio.

En los apartados subsiguientes intentaremos mostrar - a través del estudio de fuentes primarias - cómo la tecnología de la biopolítica emprenderá mecanismos que tendrán por fin último dejar morir a los indígenas fueguinos y hacer vivir al delincuente. Como hipótesis sostenemos que la coyuntura por la que atraviesa Tierra del Fuego - y la necesidad del delincuente como componente poblacional - será la que desestime las ideas deterministas y degenerativas respecto del nuevo sujeto histórico.

funcionamientos y los propios cuerpos con su materialidad y sus fuerzas». Foucault, Michel. Vigilar y castigar. Buenos Aires: Siglo XXI; 2005, p. 33.

5. Restrepo, Eduardo. Biopolítica y alteridad: dilemas de la etnización de las colombias negras. In: Restrepo, Eduardo; Rojas, Axel, eds. Conflicto e (in) visibilidad. Retos en los estudios de la gente negra en Colombia. Popayán: Universidad del Cauca; 2004, p. 271-299. 


\section{Las agencias estatal y salesiana en la colonización del indio}

En Argentina, las prácticas sociales de dominación se sirvieron de instituciones estatales y no estatales que, sin bien no tuvieron una unidad administrativa de funcionamiento respondieron a una base ideológica común que derivó en el exterminio físico y simbólico de los indígenas. Si bien los objetivos fueron similares - uniformar, adoctrinar, educar-, sus características fueron disímiles en las formas de incorporación diferencial de los indígenas al Estado-nación. Señalamos algunas de estas características en esta sección.

Indagamos en los imaginarios y las prácticas hacia la alteridad con la finalidad de dar cuenta cómo Tierra del Fuego se va perfilando como tierra libre de indios. El proyecto estatal en la isla, con la consecuente extensión de los latifundios, requerirá de la rápida solución del problema indígena. Es por esta razón que, si bien hacia fines del siglo XIX se destaca la existencia de algunos actores sociales que consideramos de importancia para explicar los procesos sociales y políticos en relación con la colonización y las políticas poblacionales del territorio ${ }^{6}$, nos centraremos en particular en la incidencia de las agencias estatal $-y$ por su intermedio la ciencia- y salesiana. Ambas agencias pondrán en funcionamiento prácticas concretas respecto del uso y el control de los cuerpos en el sentido aludido en el apartado anterior.

La reducción salesiana instalada en Río Grande ${ }^{7}$ se enmarca, además del conflicto de la época entre la Iglesia y el Estado, en la polémica esta-

6. Entre ellos sobresalen Thomas Bridges, misionero anglicano y luego estanciero, Julio Popper, explorador y propietario de El Páramo, mina aurífera de Río Grande, y los grandes latifundistas instalados desde fines de siglo XIX. Por las conflictivas relaciones que se establecieron con la misión salesiana de Río Grande, mencionamos la estancia de José Menéndez. Aunque no las desarrollamos en profundidad por razones de espacio, estas referencias nos ayudan a contextualizar los vínculos que se entablaron entre los Estados nacionales (argentino y chileno), los estancieros y los misioneros, mostrando cómo se manifestaba la presencia del Estado en el territorio.

7. Haremos alusión en este trabajo indistintamente a la agencia salesiana como misión o reducción (de La Candelaria o de Río Grande). No obstante, es importante señalar que La Candelaria —al igual que Dawson en Chile - era una reducción, donde «a diferencia de las misiones volantes, el contacto era frecuente y cotidiano, garantizando de este modo mayor eficacia en el adoctrinamiento, el impacto cultural también era más profundo y traumático». Las reducciones crearon un mundo propio y una metodología específica, donde la educación en el trabajo y la catequesis buscaban formar hábitos, adoctrinar y modificar sustancialmente a los indígenas. Nicoletti, María Andrea. Los misioneros salesianos y la polémica sobre la extinción de los selk'nam de Tierra del Fuego. Anthropologica. 2006; 24: 153-177. La misión 
blecida desde 1880 entre el evolucionismo y el creacionismo, que advierte un reforzado énfasis a partir de 1890 - tras las reformas liberales de Roca y Wilde y el declive del sector eclesiástico en la política- ${ }^{8}$. En este contexto, la adopción entusiasta del paradigma evolucionista comenzó a resultar preponderante 9 .

$\mathrm{Al}$ quedar científicamente sancionada la idea de la inferioridad de los grupos menos privilegiados desde el discurso racialista ${ }^{10}$, se recurrió a la retórica darwinista en materia de políticas poblacionales, «apelando a la inevitable y próxima extinción de la "gente salvaje" ${ }^{11}$. La idea de minoridad de los indios, permitió justificar diversos mecanismos en vistas de separar y no sustentar el papel de la iglesia, impulsando la tesis de la extinción de los selk'nam. En Tierra del Fuego, la progresiva extinción étnica estaba sucediendo al mismo tiempo que los discursos se levantaban en pro y en contra de la Iglesia y las reducciones ${ }^{12}$.

de La Candelaria funcionó en Tierra del Fuego desde el año 1893 hasta 1912, cuando Monseñor Fagnano debió vender los terrenos a la Sociedad Menéndez Behety. El propósito de la reducción — evangelizar a los indígenas - fue perdiendo sustento a partir de la progresiva desaparición de los fueguinos. Por su parte, la reducción San Rafael en Isla Dawson se fundó en 1888 y funcionó — las fechas son aproximadas - hasta el año 1911.

8. Lenton, Diana. De centauros a protegidos. La construcción del sujeto de la política indigenista argentina a través de los debates parlamentarios. Buenos Aires: Universidad de Buenos Aires; 2005, p. 136-137. Las tratativas de monseñor Fagnano en el otorgamiento de tierras para la misión de Río Grande y las dificultades con que chocó, se remontan al año 1892. Véase Bruno, Cayetano. Los salesianos y las hijas de María Auxiliadora en Argentina, vol. 2 (18951910). Buenos Aires: Instituto Salesiano de Artes Gráficas; 1983.

9. Referencias sobre la recepción del darwinismo en Argentina la encontramos en Terán, Oscar. Vida intelectual en el Buenos Aires fin-de-siglo (1880-1910). Derivas de la cultura científica. Buenos Aires: Fondo de Cultura Económica de Argentina; 2000; Salgado, Leonardo; Azar, Pablo. Evolucionismo y delincuencia: los fundamentos biológicos de la antropología criminal. In: Primeras Jornadas de Historia del Delito en la Patagonia; 2000, inédito; Vallejo, Gustavo. Los sabores del poder: eugenesia y biotipología en la Argentina del siglo XX. Revista de Indias. 2004; 64 (231): 425-444 y Girón Sierra, n. 1, entre otros.

10. Seguimos a Todorov para definir este concepto, que se diferencia del de racismo, visto este último como un dominio del nivel del comportamiento o del sentido común. El racialismo entonces, se reserva a las doctrinas. «Así, el sometimiento de las razas inferiores, o incluso su eliminación, se puede justificar gracias al saber acumulado en materia de razas. Es aquí donde el racialismo se reúne con el racismo: la teoría da lugar a la práctica». Todorov, Tzvetan. Nosotros y los otros. México D.F.: Siglo XXI; 1991, p. 115 y 119.

11. Lenton, n. 8, p. 137.

12. Aclaramos que hablaremos con suma cautela de la extinción que suele adjudicarse a las etnias de Patagonia — sobre todo las fueguinas-. El supuesto de considerar grupos étnicos puros se desintegra con el mestizaje. Éste, al romper con la idea de pureza, rompe con la idea de 
A principios de siglo la isla en materia de indios ha quedado en el recuerdo. Para el discurso oficial, las verdaderas causas del despueble son las enfermedades, restándole responsabilidad a las actuaciones tanto de los estancieros y viajeros, como de la misma policía del territorio. El hecho de que las epidemias sean el origen de la extinción por excelencia, exime de culpa y cargo al hecho empírico de las matanzas reiteradas hacia ellos y los cambios socio-culturales en sus modos de vida, a partir de la llegada de los blancos ${ }^{13}$.

Una parte importante en esta discusión establecida en el plano político entre el Estado y la Iglesia es la participación en ella del gobernador territoriano Pedro Godoy ${ }^{14}$. Godoy presume que la misión de Río Grande, no sólo es un centro educativo adaptado a la modalidad nómade del indio, sino también «involuntariamente refugio de malhechores legales [ya que] recibe a menudo informes de las comisarías a donde los indios acuden en busca de comida y protección» ${ }^{15}$.

En el contexto finisecular, el espíritu de los primeros gobernadores fueguinos (Paz, Cornero y Godoy) fue prácticamente el mismo, el cual consideramos por lo menos contradictorio. Por un lado, se señalaba lo indispensable de conformar una colonia estatal en el continente, negando de esta forma una colonia religiosa, como lo fue La Candelaria. La necesidad de mano de obra, recurrente en las fuentes, es interesante en este punto, en vistas de su utilización por el Estado: «hay indios con aptitud para profesiones como la navegación» ${ }^{16}$. Y aunque los expedientes en su

grupo étnico esencial. La habilitación de la descendencia por la vía del mestizaje —además de la autoadscripción-, da por resultado la visibilidad de una etnia bajo dichos términos.

13. El proceso de extinción de los selk'nam y sus causas es analizado en profundidad por Nicoletti, n. 7, p. 155.

14. Pedro Godoy (1858-1899) prestó servicios en la Conquista del Desierto y también formó parte de las expediciones al Chaco y Formosa. Siendo uno de los gobernadores más progresistas, tendrá un papel decisivo en la radicación del penal fueguino y en la promoción de la colonización penal. Entre otras acciones, Godoy envía un informe al ministro del Interior en 1893 proponiendo medidas conducentes al mejor y más pronto desarrollo del penal y en 1896 un proyecto donde expone sus ideas sobre las bases del régimen a que deben estar sometidos los penados, los trabajos que deberían realizar y el criterio para la selección del personal civil. Referencias de este rol de Godoy las encontramos en García Basalo, J. Carlos. La colonización penal de la Tierra del Fuego. Buenos Aires: Marymar; 1988.

15. Belza, Juan. En la isla del fuego: Encuentros. Buenos Aires: Instituto Salesiano de Artes Gráficas; 1974, p. 324.

16. Belza, n. 15, p. 326. 
mayor parte terminen en archivo, estas alusiones indican la necesidad de que sea el Estado y no la Iglesia quien controle y usufructúe el trabajo indio.

Pero por otro lado, no cabía duda que la misión - sobre todo en su carácter de reducción, con su posibilidad de congregar y convertir- cumplía el no menor cometido de alejar a los indios de las estancias, una de las mayores dificultades a partir de la conformación de estas últimas. De aquí que el Estado en cierta medida apoyara el proceso de evangelización ${ }^{17}$. La agencia salesiana tenía un complemento que podía beneficiar al Estado: la enseñanza compulsiva de diferentes oficios en los talleres preparados para tal fin (hilado y trabajos en el campo en el lado argentino; aserradero en el lado chileno). Luego de un aprendizaje constante y disciplinar los indígenas podrían ser explotados a conveniencia por los distintos actores sociales.

No obstante, en vistas del proyecto estatal en la isla, y la rápida instalación de las grandes estancias en el territorio,

«lo que menos interesaba al gobierno argentino, cuya política pasó de la violencia a la indiferencia, era donar tierras que no sólo no le redituaban ningún beneficio sino que al ser fraccionadas contrariaban la política latifundista» ${ }^{18}$.

En este estado de cosas, la reducción de Río Grande no contó con un apoyo del Estado, a diferencia de la misión de Isla Dawson, del lado chileno de la Tierra del Fuego - monseñor Fagnano, en 1890, logró que se escriturara públicamente por decreto del gobierno una concesión por veinte años a los salesianos-.

Pervive sin embargo en las fuentes una profunda contradicción. Para ambas agencias - estatal y salesiana-, los indígenas se encontraban en estadios inferiores en la escala evolutiva. La barbarización era una conclusión aceptada derivada de los hábitos sociales tejidos históricamente, relacionados con los vicios, la indolencia, la pereza, etc. Así, los objetivos y la metodología reduccional no difería de otras praxis estatales; esto es, un adoctrinamiento intenso de la fe católica y la búsqueda de uniformidad de las diferencias étnicas. Lo que se buscaba era efectivizar las prácticas

17. En este sentido, la reducción Nuestra Señora de La Candelaria, de la congregación salesiana tuvo, para bien o para mal, una incidencia relevante en relación con el problema del indio en Tierra del Fuego.

18. Nicoletti, n. 7, p. 156. 
sedentarias, estrechamente vinculadas con la civilidad, el trabajo productivo y la escolarización ${ }^{19}$.

Ahora, si bien la extinción inevitable de las etnias fueguinas era un hecho para la gobernación del territorio - intermediaria del poder centraly la agencia salesiana, ésta última continuaba apostando porque el indio, a partir del contacto con la civilización, pudiera ascender en el camino hacia ella ${ }^{20}$. Una posición diferente no obstante, adoptó el poder político. Con el objetivo de poblar la porción más austral del territorio nacional por inmigración elegida, la desaparición étnica no constituía un problema; aquellos indios que sobrevivieran lo harían, tal como lo indicaba Payró en 1898 y Holmberg en $1902^{21}$, gracias a los beneficios del mestizaje y la predominancia de los genes de los individuos superiores.

En síntesis, el trato diferencial y la segregación fue algo compartido por ambas agencias. La única forma viable para la incorporación del indio tenía que ver, igual que en el resto de los mecanismos puestos en marcha en el proceso de ciudadanización, con el abandono de las pautas culturales (formas de trabajo, vestidos, condiciones de vida, etc.) y la consecuente homogeneidad de las diferencias étnicas.

\section{La colonización bioantropológica}

Registramos una serie de sucesos, a fines del siglo XIX y comienzos del siglo $\mathrm{XX}$, que nos permiten evaluar las conexiones que se establecieron entre la política y la ciencia. Los resultados de dichos acontecimientos (artículos, exposiciones, fotografías) nos ceden la posibilidad de medir el alcance de la biopolítica y las formas en que se visibilizaron los grupos indígenas. En todos los casos, el elemento indio se convierte en evidente exponente

19. Nicoletti, n. 7, p. 155. Conceptos tomados de Carrasco, Morita. Los derechos de los pueblos indígenas en Argentina. Buenos Aires: IGWA; 2000, p. 29. La idea matriz de la concentración y el intento de argentinización, se propició a través de una retórica tendiente a instalar casas de las familias indígenas, dispuestas en orden simétrico y formando pueblo. Entraigas, Raúl A. Monseñor Fagnano. El hombre. El misionero. El pionner. Buenos Aires: S.E.l; 1945, p. 399. Todas las prácticas de la agencia salesiana apuntarán a esta finalidad.

20. La posibilidad de redención estaba dada por la afirmación de la unicidad del género humano.

21. Payró, Roberto. La Australia argentina. Buenos Aires: CEAL; 1982 y Holmberg, Eduardo. Viaje al interior de Tierra del Fuego. Buenos Aires: Anales del Ministerio de Agricultura. Sección de Inmigración. Propaganda y Geografía; 1906. 
del proceso de subalternización ${ }^{22}$. Se observan también de forma clara las prácticas de la época llevadas a cabo por los científicos y, en general, por el conjunto de técnicos que configuran la microfísica del poder: la obsesión por el registro antropométrico, la certeza de los investigadores y funcionarios de la inminente desaparición de los sujetos estudiados y el refuerzo a través de la imagen fotográfica de la tesis de un país sin indios. Los métodos empleados permitirían recuperar datos morfológicos confiables y comparativos que harían posible una correcta clasificación racial ${ }^{23}$.

\subsection{Taxonomización y registro}

En el año de 1895, el gobernador de Tierra del Fuego Pedro Godoy solicita a Francisco Moreno, el envío de algunos naturalistas para el estudio de «estas lejanas zonas» ${ }^{24}$. El Dr. Fernando Lahille, experto en clasificaciones de especies naturales, tuvo la oportunidad de fotografiar a una tribu «Oona» [sic] de ochenta y ocho indígenas traídos de San Sebastián a Ushuaia ${ }^{25}$. Las

22. Nos situamos, para hablar de este proceso, en la línea de la descolonización del conocimiento. Remitimos, entre otros, a los trabajos compilados en Lander, Edgardo, comp. La colonialidad del saber: eurocentrismo y ciencias sociales. Perspectivas Latinoamericanas. Buenos Aires: CLACSO; 2003.

23. Maturana, Felipe. Fotografía fueguina y antropología regional (1895-1931). Una mirada desde la Antropología Visual. In: Alvarado, Margarita; Odone, Carolina; Maturana, Felipe; Fiore, Danae, eds. Fueguinos. Fotografías siglos XIX y XX. Imágenes e imaginarios del fin del mundo. Santiago de Chile: Pehuén; 2007, p. 49-60.

24. Explorador y naturalista, Francisco P. Moreno (1852-1919) fue uno de los fundadores de la Sociedad Científica Argentina y el fundador del Museo de La Plata en 1884. En la actualidad es cuestionado por amplios sectores de la intelectualidad por su activo papel en el proceso de museologización y conversión de los indígenas en ancestros. En este sentido, véase Quijada, Mónica. Ancestros, ciudadanos, piezas de museo. Francisco P. Moreno y la articulación del indígena en la construcción nacional argentina (siglo XIX). EIAL (Estudios Interdisciplinarios de América Latina y el Caribe) [publicación seriada en Internet]. 1998; 9 (2): s/n. Disponible en: http://www.tau.ac.il/eial/IX_2/quijada.html [citada 2 Mar 2011]; Andermann, Jens. Mapas de poder. Una arqueología literaria del espacio argentino. Rosario: Ed. Beatriz Viterbo; 2003, p. 120-128; Navarro Floria, Pedro; Salgado, Leonardo; Azar, Pablo. La invención de los ancestros: El «patagón antiguo» y la construcción discursiva de un pasado nacional remoto para la Argentina (1870-1915). Revista de Indias. 2004; 64 (231): 405-423; Pepe, Fernando; Añón Suárez, Miguel; Harrison, Patricio. Grupo Universitario de Investigación en Antropología Social [GUIAS]. Identificación y restitución: «Colecciones de restos humanos en el Museo de La Plata». Buenos Aires: Editorial de la campana; 2008.

25. Maturana, n. 23. Es probable que estos indígenas estuvieran detenidos en Ushuahia, derivado de la flagrante situación de violencia que vivían por parte de los blancos. 
láminas de Lahille, seis en total, fueron publicadas en 1926 en la Revista del Museo de La Plata ${ }^{26}$ (Figuras 2, 3, 4).
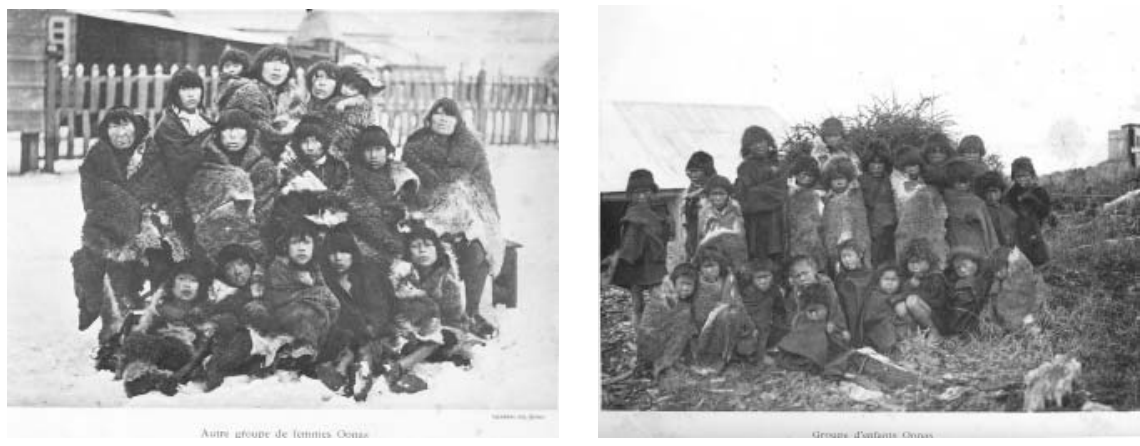

Figura 2. Lámina número 2 de Fernando Lahille (1896) y Pedro Godoy. Fuente: Lahille, Fernand. Matériaux pour servir a I' historie des oonas. Indigènes de la Terre de Feu. Revista del Museo de La Plata. 1926; 29: 339-361.
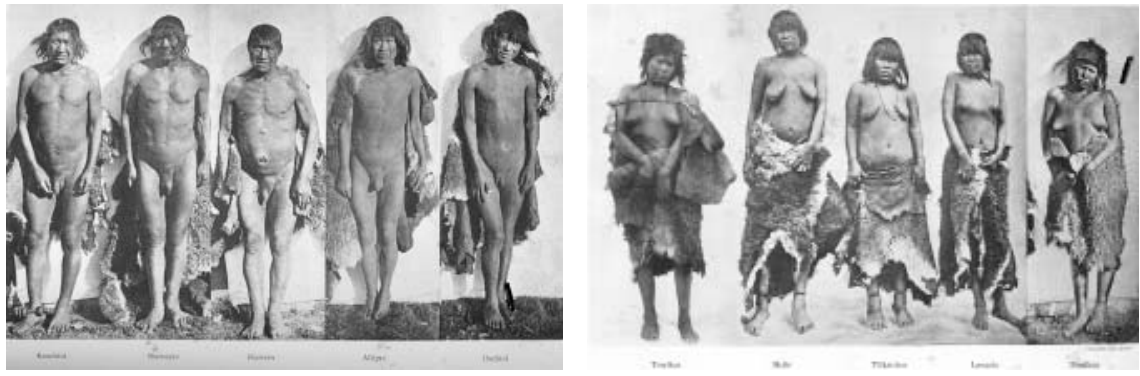

Figura 3. Lámina número 3 de Fernando Lahille (1896) y Pedro Godoy. Fuente: Lahille, Fernand. Matériaux pour servir a l' historie des oonas. Indigènes de la Terre de Feu. Revista del Museo de La Plata. 1926; 29: 339-361.

26. Lahille, Fernand. Matériaux pour servir a l' historie des oonas. Indigènes de la Terre de Feu. Revista del Museo de La Plata. 1926; 29: 339-361. El trabajo de Lahille se inscribe en el apogeo de las ciencias naturales, que tuvo como principal característica la clasificación y la taxonomización de plantas y animales, incluyendo el ser humano. La descripción y clasificación de las razas se volvería central en la Antropología. 

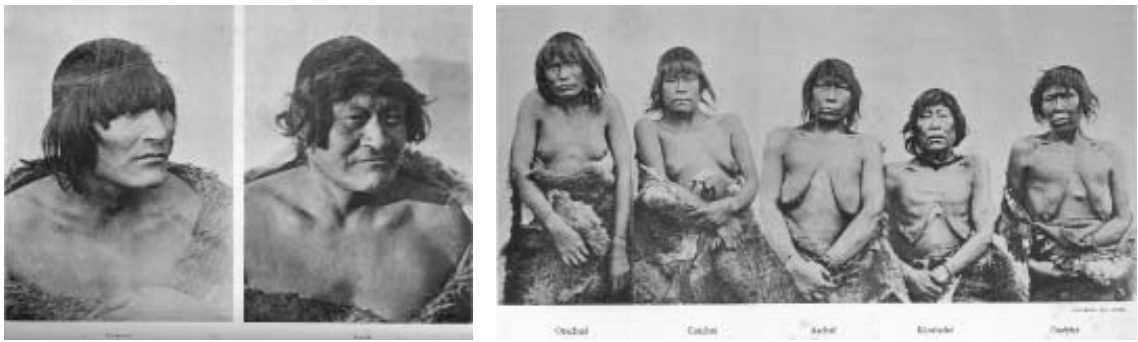

Figura 4. Lámina número 5 de Fernando Lahille (1896) y Pedro Godoy. Fuente: Lahille, Fernand. Matériaux pour servir a l' historie des oonas. Indigènes de la Terre de Feu. Revista del Museo de La Plata. 1926; 29: 339-361.

Bajo el principio de estandarización en pos de la clasificación fenotípico/ racial, las fotografías antropológicas solicitadas y hechas por antropólogos, iban en general acompañadas por minuciosas tablas antropométricas donde figuraban las medidas absolutas y las medidas relativas ${ }^{27}$.

Por otro lado, además de la impronta disciplinar de las fotografías, observamos el papel activo que tiene el Estado en su composición. Consideramos que en la búsqueda por «registrar los principales rasgos anatómicos y fenotípicos de los individuos» ${ }^{28}$ el interés, mediado por el gobernador territoriano - representante del Estado Nacional- es el control bioantropológico y directamente ligado a ello, el control político de los sujetos sometidos.

\subsection{Paradigma de la extinción}

En el año 1898 el antropólogo alemán Lehmann-Nitsche realiza un estudio sistemático de los caracteres físicos de los Onas durante una exposición que se realiza en Buenos Aires, cuya atracción la representaban dos familias enviadas allá desde sus comarcas lejanas por el gobernador Pedro Godoy. Dicho estudio «va acompañado por mediciones, descripciones y fotografías individuales» ${ }^{29}$. El artículo, escrito en francés, muestra a las claras el papel de Pedro Godoy en la exposición:

27. Lehmann-Nitsche, Robert. Études Anthropologiques sur les indiens Ona (groupe Tshon) de la Terre de Feu. Revista del Museo de La Plata. 1915; 33: 174-184 y Lehmann-Nitsche, Robert. Estudios Antropológicos sobre los onas (Tierra del Fuego). Anales del Museo de La Plata. 1927; 2: 57-99.

28. Maturana, n. 23, p. 50.

29. Lehmann-Nitsche, 1915, n. 27. 
«En octubre de 1898, el coronel Pedro Godoy, gobernador de la Tierra del Fuego, envió a la Exposición Nacional de Buenos Aires dos familias de indios Ona, que estaban ubicados en una tienda de campaña. Los indios habían contribuido con todo el bagaje ergológico de su civilización primitiva, y durante las horas de visita, el público se precipitaba para contemplar este espectáculo exótico para la capital de la Argentina» ${ }^{30}$.

La atracción era el tableau vivant que estas familias arrojaban, remontando al público a tiempos prehistóricos ${ }^{31}$ (Figura 5).

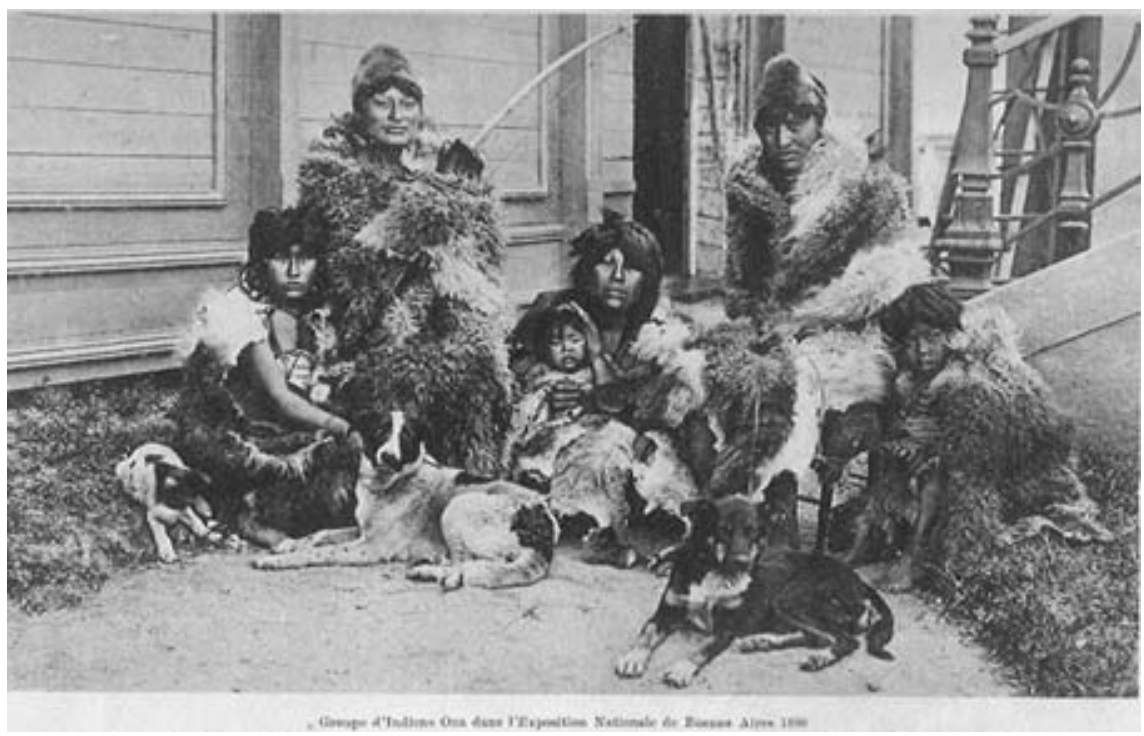

Figura 5. Grupo de indios onas enviados dentro de la Exposición Nacional de Buenos Aires 1898. Fuente: Lehmann-Nitsche, Robert. Études Anthropologiques sur les indiens Ona (groupe Tshon) de la Terre de Feu. Revista del Museo de La Plata. 1915; 33: 174-184.

30. Lehmann-Nitsche, 1915, n. 27, p. 174.

31. Es interesante constatar - por razones de espacio y la temática de este dossier no lo expondremos en profundidad- la presencia de dos modelos en supuesta tensión. El indio salvaje/exótico que podemos observar en las fotografías de la exposición de 1898 —y que se reproducen en la antropología visual etnográfica-, parecen contraponerse con las que muestran la conversión de los fueguinos al trabajo en las misiones de Dawson y La Candelaria. La disímil incorporación indígena queda reflejada así en esta contraposición, retratando una realidad tendiente a la conversión (trabajos en las misiones), y otra más cercana al salvajismo - pieles, uso de arco y flecha-, en donde la máxima alteridad cultural estaría denotando la imposibilidad de asimilación de los fueguinos o el mérito de la Iglesia en hacerlo. 
La historia de Godoy con las nóminas y fotografías, no era nueva. Pedro Godoy hará uso de todas las representaciones posibles aliadas a su discurso. Así, los reclamos del gobernador irán acompañados de listas nominales de los indios a los que alude, corroborados por fotografías que incorpora al expediente. Por otro lado, esta alusión de Lehmann-Nitsche a «les temps préhistoriques» enriquece la mirada hacia un gobernador que extingue a los pobladores indígenas antes de que la realidad lo hiciera étnicamente.

Posteriormente, en 1902, el antropólogo viaja a Tierra del Fuego, junto con Eduardo Holmberg ${ }^{32}$. Realiza observaciones antropológicas y mediciones antropométricas de 20 hombres y 30 mujeres ona. Entre las particularidades descritas y tabuladas minuciosamente en cuadros métricos, se estudian el color del cutis, el color del iris, el pelo, la cabeza, el índice cefálico, el índice facial y la talla corporal en todas sus dimensiones. Para ello,

«mientras [Holmberg y sus compañeros italianos] se detuvieron en el destacamento de Río Grande, me trasladé a la vecina misión de los Padres Salesianos que me hospedaron con verdadera simpatía. Durante varios días, pude así estudiar y medir un gran número, tanto de hombres como mujeres, ofreciéndose los padres mismos a hacer todos los preparativos y apuntar las cifras métricas que les dictara. Si llegué a realizar un trabajo antropológico, algún día tal vez de importancia, sólo pudo ser hecho gracias a la abnegada ayuda de los misioneros que se interesaron en sumo grado por mis investigaciones» ${ }^{33}$.

Tierra del Fuego contribuyó con los intereses del Estado-Nación consolidado en la construcción del territorio nacional como una formación social. Estudios de este tipo redescubren el hecho de que la ciencia fuera un acompañante infatigable de las políticas de Estado. Al mismo tiempo, este Territorio Nacional contenía un plusvalor: la máxima alteridad conferida a las etnias fueguinas y su imposibilidad de cara a la argentinización ${ }^{34}$. Bajo esta

32. Eduardo L. Holmberg es nombrado Naturalista viajero del Ministerio de Agricultura de la Nación para realizar un viaje de exploración a Tierra del Fuego. Los resultados son publicados en 1906. Holmberg, n. 21.

33. Lehmann-Nitsche, 1927, n. 27, p. 64.

34. Las ideas de mínima y máxima alteridad son expuestas por Delrio, Walter. Argentinos colonos o chilenos intrusos: territorializaciones y clasificación de los pobladores indígenas en Patagonia. Anuario IEHS. 2006; 21: 96-111. 
premisa, el poder político emprendería mecanismos alternativos de control poblacional. No resulta paradójico que este obstáculo a la civilización que representaba el elemento indio se produjera en momentos de exploración y necesidad de poblamiento efectivo de la región, que redundaría en el establecimiento de las grandes estancias hacia fines de siglo.

\section{El penal de Ushuaia: ¿contraimagen citadina o contracara del ideal de normalidad de la nación?}

Iniciamos este apartado con algunos interrogantes: ¿el penal de Ushuaia se cristaliza como la contraimagen citadina de Buenos Aires; esto es, como metrópolis a ser imitada, o como la contracara del ideal de normalidad de la Nación? Las miradas que pueden tomarse respecto de la prisión más austral de la República son múltiples en este sentido. Pero lo que queda claro es que su creación partió de un problema de tipo coyuntural, teniendo como meta principal poblar el territorio y la definición de los límites con Chile - con la consecuente soberanía nacional sobre el extremo sur- ${ }^{35}$.

Partiendo de esta premisa, avanzaremos sobre dos ejes. En primer lugar, el penal en el ideario de colonización del territorio; y dentro de él, la decisión última de que fueran los criminales quienes poblaran la ciudad. En segundo lugar, ligado al componente poblacional - los delincuentes-, la utilización de bases científicas en la identificación, corrección y control de los a-sociales traídos desde la metrópolis ${ }^{36}$.

35. De hecho, la adopción del sistema europeo de deportación sufrió una deformación en América Latina, respondiendo a las condiciones locales. Del Olmo, Rosa. América Latina y su criminología. México D.F.: Siglo XXl; 1981. Seguimos a la autora en lo referente a la reconstrucción histórica de la criminología como campo de conocimiento en América Latina.

36. Estudiaremos las relaciones de poder, las tecnologías de control, y la microfísica del poder presente en la sociedad disciplinar a partir de la visión foucaultiana del régimen penitenciario. Afirmaremos, con el autor, que en él existen «un conjunto de elementos materiales y de técnicas que sirven de armas, de relevos, de vías de comunicación y de puntos de apoyo a las relaciones de poder y de saber que cercan los cuerpos humanos y los dominan haciendo de ellos un objeto de saber». Foucault, n. 4, p. 35. 


\subsection{Colonización penal}

La Cárcel de Reincidentes de Tierra del Fuego transita el período en polémicas y debates. En el año 1886, Eduardo Wilde ${ }^{37}$, quien fuera encargado de la instalación del penal, dio cuenta de los propósitos principales que estaban en danza respecto de lo que se denomina en la jerga penológica, colonización penal ${ }^{38}$. La colonización penal, como expresión de una política eliminatoria y utilitaria, combínase no en pocas ocasiones con claros y mal disimulados objetivos de expansión territorial ${ }^{39}$.

El proyecto de la colonia penal en el Departamento de Ushuaia será la más clara política colonizadora en la isla. En materia simbólica además, la colonia penal «no era sólo una manifestación del estado, sino su única manifestación. El estado nacional -y la cultura Argentina moderna- llegaron a Ushuaia bajo la forma de una prisión» ${ }^{40}$. La piedra fundamental de la cárcel de reincidentes será colocada a comienzos de 1896, en precarias instalaciones, confiando el poder ejecutivo al gobernador Godoy su organización. El gobernador, además de atribuirse su fundación «por iniciativa del que suscribe», afirma: «Estas colonias penales son muy útiles en un territorio desierto, cuando los hombres que se envían á ella, todavía son aptos para algo ${ }^{41}$ (Figura 6).

37. El Dr. Eduardo Wilde (1844-1913), como segundo Ministro de Justicia, Culto e Instrucción Pública (11/02/1882-12/10/1886), en la primera presidencia de Roca, suscribe el mensaje y proyecto de ley por el que se crea una colonia penal en la Tierra del Fuego.

38. El concepto de prisión es tomado de Foucault, n. 4, y el de colonia penal de Pimentel. Juan. En el panóptico del Mar del Sur: orígenes y desarrollo de la visita australiana de la Expedición Malaspina (1793). Madrid: Consejo Superior de Investigaciones Científicas; 1992. Utilizamos para este trabajo, no obstante, de manera indistinta los términos de cárcel, prisión y colonia penal.

39. García Basalo, n. 14, p. 1. La colonización penal se define como la preparación por la mano de obra penal de la colonización libre. Así entendida, es esencialmente temporaria. Su finalidad primordial es atraer y facilitar la inmigración libre. Debe, pues, preparar lo necesario para recibirla y desaparecer tan pronto como ella alcance la consistencia indispensable para subsistir por sí misma. Cumplida la misión, constituye un grave error prolongar más allá de ese momento la coexistencia de la colonización penal y de la colonización libre. Cuche, Paúl. Traité de science et de législation pénitentiaires. Paris: Librairie Générale de Droit et de Jurisprudence; 1905.

40. Caimari, Lila. Una sociedad nacional-carcelaria en la frontera argentina (Ushuaia, 1883-1947). In: Primeras Jornadas de Historia del Delito en la Patagonia; 2000, inédito.

41. Godoy, Pedro. Memoria de la Gobernación de Tierra del Fuego presentada al Ministro del Interior, correspondiente a los años 1898-1899 (Tomo 2. Anexos). Buenos Aires: Imprenta la Piedad; 1899, p. 271. 


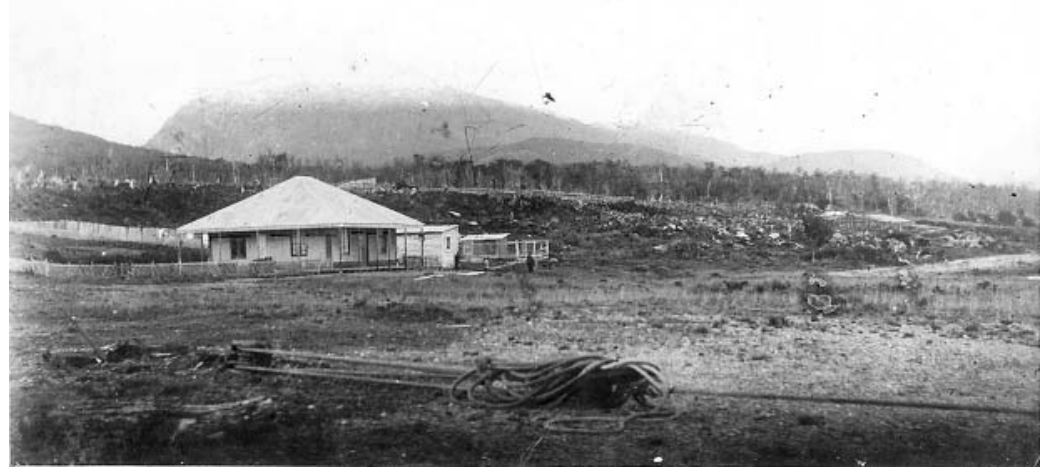

Figura 6. Presidio de Ushuahia, año 1898. Fuente: Archivo Central Salesiano. Caja 201: Indígenas. Testimonios de malos tratos. Serie de notas del P. Lorenzo Mazza sobre indígenas del Sur Patagónico. «90 años de acción salesiana». Los indios de la Patagonia hacia 1879.

Aunque no conforme Godoy con las aptitudes de los nuevos colonos, el penal alcanzaba objetivos inmediatos. Por un lado solucionar el problema demográfico acuciante del territorio; por el otro, ponía freno a la escoria citadina al enviarla al confín del mundo. Respecto al incremento de población, según el Segundo Censo Nacional del año 1895 Ushuaia tenía 39 casas, la misma cantidad de familias, con un total de 131 habitantes no indígenas. En el lustro 1890-1894, Tierra del Fuego sólo recibió 26 inmigrantes sobre un total de 137.893 internados y colocados oficialmente en el país por la Dirección de Inmigración ${ }^{42}$.

El incremento de la población y el impulso del progreso fueguino, se refleja en las fuentes oficiales. Juan Alsina indica que, en los quince años que van de 1895 a 1909 ,

«la cifra [de inmigrantes] se eleva a 542, lo que da una media anual de 36 inmigrantes. La presencia de los condenados parece no ejercer ninguna influencia desfavorable sobre la inmigración pues Tierra del Fuego en ese período supera a Formosa (411), se acerca a Catamarca (581) y no está muy lejos de Neuquén (632)» ${ }^{43}$.

\footnotetext{
42. Alsina, Juan A. La inmigración en el primer siglo de la independencia. Buenos Aires: Felipe S. Alsina; 1910, p. 35.

43. Alsina, n. 42, p. 35.
} 
La cárcel se recrea, señala Caimari, como una de las paradojas de la historia de la formación del Estado argentino, en la que «los ciudadanos más duramente castigados por el estado moderno se convertirían en los representantes (forzados) del estado y la modernidad en los bordes territoriales de su soberanía ${ }^{44}$. En dicha paradoja, la apropiación de los cuerpos de los condenados, públicamente obligados a trabajar, se vincula con la garantía de la existencia del asentamiento, gracias a la mano de obra de la prisión ${ }^{45}$.

De manera casi paralela a la creación de la cárcel como penal para reincidentes, y su población circunscrita bajo la figura de criminales incorregibles, la prisión se fue convirtiendo en lo que podríamos denominar una cárcel para todos. Los reincidentes cumplían sus penas demasiado rápido, producto de las características del delito cometido - en su mayoría, contra la propiedad-, lo que no permitía la constitución de los mismos en potenciales pobladores o pobladores estables. Por esta razón, la cárcel fue progresivamente convirtiéndose en presidio, para los penados que debían cumplir condenas más largas (el homicidio fue, a largo plazo, el crimen asociado a más de la mitad de la población carcelaria) ${ }^{46}$. Los menores comenzaron a engrosar las filas del aprendizaje de oficios, para hacer de ellos hábiles operarios aplicados a la industria de la madera ${ }^{47}$. La pena aquí se combinaba con la preparación para el trabajo de este contingente poblacional $^{48}$. El año de 1890 muestra así un nuevo giro; el penal comienza a recibir todo tipo de condenados. Paulatinamente llegarán a

44. Caimari, Lila. Apenas un delincuente. Crimen, castigo y cultura en la Argentina, 1880-1955. Buenos Aires: Siglo XXI Editores; 2004, p. 69.

45. Caimari, n. 44, p. 68.

46. Caimari, n. 44, p. 69.

47. El gobernador Pedro Godoy hace alusión a esas «decenas de muchachos desheredados que vagan por las calles de la capital expuestos a ser presa de los vicios que engendran la miseria y el desamparo». Godoy, Pedro. Memoria de la Gobernación de Tierra del Fuego presentada al Ministro del Interior, correspondiente a los años 1893-1894. Buenos Aires: Argos, Imprenta y Encuadernación; 1894, p. 45.

48. García Basalo, n. 14, p. 121. Wilde sostenía, en el Mensaje y Proyecto de la colonia penal: «No tenemos una casa para la corrección de los menores criminales [...] Entretanto, fácil sería establecer en el presidio, un departamento aislado, donde aquellos y aún los que, sin ser criminales, no hayan podido ser dominados en sus inclinaciones por sus padres, sintieran los efectos de una vida nueva y ruda, propia para despertar una reacción saludable». Wilde, Eduardo. Memoria presentada al Congreso Nacional de 1883. Buenos Aires: Imprenta de La Tribuna; 1883, p. 936. Cursivas en el original. 
convivir menores, presos políticos y hombres acusados de abigeato, entre otras causas ${ }^{49}$.

De esta manera, los condenados en Ushuaia no hicieron otra cosa que fundar las bases de la localidad, ladrillo por ladrillo, mediante el trabajo. Godoy observa:

«Esta cárcel fue fundada con el fin, no solo de guardar y regenerar los individuos destinados a ella, sino también y principalmente con el hacer lo posible para que los penados cumplidos que fueran aptos para el trabajo, así como los menores que resultaren de índole laboriosa, se incorporaran á su población efectiva ${ }^{50}$.

\subsubsection{Los criminales: los sujetos del progreso del territorio}

En la decisión acerca de quiénes deberían ser los sujetos del progreso del territorio, se conjugaron una serie de consideraciones. Roberto Payró exhibe las dos aristas que comprendía la cuestión de la población de los territorios en las décadas posteriores a la conquista en «la Australia argentina». Sintetizando su pensamiento Navarro Floria expone:

«Uno era el de la inmigración ultramarina, y en este sentido entra en contacto con la cuestión general de la inmigración europea en la Argentina. El otro aspecto es el de la población indígena, cercano a la cuestión de la construcción étnica de la nación ${ }^{51}$.

Pero una serie de drásticos cambios aceleraron el proyecto de destierro punitorio como recurso civilizatorio: la abrupta caída de la población indígena desde el contacto con el blanco y el consecuente cierre de las misiones religiosas - tanto la anglicana como la salesiana-, la muerte de Popper en 1893, quien además de haberse opuesto siempre a la creación

\footnotetext{
49. Archivo Central Salesiano, Buenos Aires, caja 201. Ushuaia.

50. Godoy, n. 41, p. 271

51. Navarro Floria, Pedro. Patria sin pueblo: La mirada del reformismo liberal sobre los Territorios del Sur argentino. In: Segundas Jornadas de Historia de la Patagonia; 2006, inédito.
} 
de una prisión, dejaba detrás El Páramo ${ }^{52}$, que desaparecería con él, y la llegada al territorio del emprendedor coronel Pedro Godoy ${ }^{53}$.

Como consecuencia encontramos una contradicción entre el discurso y la práctica - demasiado permisiva para los presos $^{54}$ - . En cuanto al discurso, el penal fueguino nació con una meta claramente fijada por la política criminal del momento, asentada en férreas bases científicas. Los comportamientos considerados anómalos en relación con la creación de un modelo de ciudadano orientado al trabajo productivo y con hábitos sociales deseados - vinculados a la moral, la higiene, el trabajo y la buena conducta - debieron ser contrarrestados con proyectos modernizadores desde el Estado Nacional. La ejecución del castigo, a través de la pena privativa de la libertad desde finales del siglo XIX,

«adquirió una fuerte orientación hacia el orden, la educación, el trabajo y la formación religiosa con el objetivo de - una vez cumplida la pena de prisión- devolver a la sociedad un ciudadano recuperado, regenerado, en síntesis, "resocializado" ${ }_{\gg} 55$.

El marco de discusión de estas ideas se asienta en una concepción originalmente médica de la higiene que deriva hacia el concepto de higiene social, basada en la detección y profilaxis de patologías sociales. Consideramos que la premisa de la profilaxis social como prevención, ubicada en el

52. Julio Popper, ingeniero y aventurero, rumano de origen, se había establecido en El Páramo, una mina de explotación aurífera en Río Grande. Realizó expediciones científicas y geográficas enviado por el Instituto Geográfico Argentino, participó activamente en la caza de indios y fue denunciado por ésta desde diversos frentes. A su llegada a la Argentina, entabló relaciones con los círculos más cercanos al poder, adoptó la doctrina positivista, y puso en duda la autoridad de la religión, en consonancia con el anticlericalismo dominante en ciertas instancias de poder. Pero en su propio territorio, Popper era el Estado. Popper tenía un poder enorme y puso, hasta su muerte, sobre tela de juicio la verdadera incidencia del Estado argentino en el territorio.

53. Caimari, n. 44, p. 66.

54. Bohoslavsky señala que «la regulación del Estado-nacional sobre la población [...] no pasaba de ser una mera declaración de efectos cosméticos: los penados trabajaban más tiempo afuera de la cárcel que en cualquier institución carcelaria». Bohoslavsky, Ernesto. Curando la nación: los médicos y la formación del estado en Argentina. A-Contracorriente. 2007; 4 (3): 188-201.

55. Navas, Pablo. Esos económicos brazos. El trabajo de los presos de la cárcel de Río Gallegos. In: XII Jornadas Interescuelas-Departamentos de Historia, 2009, inédito. 
centro del debate político y científico, en la cotidianeidad de las prácticas, coadyuvó al sostenimiento de un sistema eugenésico como praxis política ${ }^{56}$.

Sin embargo, a diferencia de las ambigüedades observadas respecto de la población indígena, donde los discursos apuntan a una genealogía que marcará el triunfo de una nación eugenésica, en Ushuaia, la solución del problema criminal mediante la eliminación de los criminales, permite observar una visión al menos sorpresiva: su regeneración casi inevitable, al exportar al desierto los resultados perversos de la urbanización porteña ${ }^{57}$.

\subsubsection{Un gabinete de control y observación}

La Cárcel de Reincidentes fue, como toda institución carcelaria moderna, un signo del desarrollo de los medios de control del Estado sobre la sociedad, y por ende un indicador de su estadio de formación ${ }^{58}$. La ciencia con sus propósitos normalizadores y de regulación social dieron a Tierra del Fuego -Territorio Nacional desde 1884- un carácter simbólico, al convertir a la isla en un campo de aplicación de teorías y reflexiones epocales. En este contexto, la utilización del modelo de análisis higiénico para explicar el proceso social derivó en la individualización de una población de delincuentes que vivía dentro de las fronteras nacionales y que debía ser identificada y controlada o reformada ${ }^{59}$.

56. El concepto de eugenesia y eugenesia latina ha sido trabajado entre otros, por Álvarez Peláez, Raquel. Introducción. Asclepio. 1999 (51) 2: 5-10 y Miranda, Marisa; Vallejo, Gustavo, comps. Darwinismo social y eugenesia en el mundo latino. Buenos Aires: Siglo XXI; 2005.

57. Caimari, n. 44. Creemos que esta idea del envío de los representantes de la mala vida a Ushuaia deriva del discurso criminológico de la reincidencia, que define la recaída en el delito como un agravante. En la memoria de justicia de 1894 se puede leer: «La ley ha considerado justamente que la reincidencia es una circunstancia agravante del castigo que inflige al delito en sí mismo, viendo en la reiteración del último el síntoma de una perversión mayor del agente, y el indicio de un peligro social más inminente, lo que determina la aplicación de una pena nueva y más eficaz». Memoria del Ministro de Justicia, Culto é Instrucción Pública, correspondiente al año de 1894. Tomo 1. Buenos Aires: Taller Tipográfico de la Penitenciaría Nacional; 1895, p. 334.

58. Caimari, n. 40.

59. Salessi, Jorge. Médicos, maleantes y maricas. Higiene, criminología y homosexualidad en la construcción de la nación Argentina (Buenos Aires 1871-1914). Buenos Aires: Beatriz Viterbo Editora; 1995, p. 28. 
En consonancia con dichas ideas, al igual que la Policía de la Capital, el penal poseía un gabinete antropométrico ${ }^{60}$. En un contexto de endurecimiento de disciplinas tales como la criminología, la psiquiatría, la antropología criminal y la sociología criminal, la identificación de los elementos disruptores permitía consagrar una tipología de homogenización de determinados grupos sociales. Esto, en vistas del peligro que podían llegar a investir, producto de "caracteres fisiológicos y morales los cuales orientaban "naturalmente" a ciertos grupos étnicos hacia la ruptura del pacto social» ${ }^{61}$.

El análisis científico de definición de lo moral, la idea de tendencia a lo criminal o naturaleza criminal, ampliaba el axioma de la época que señalaba que los caracteres morfológicos explicaban ciertos comportamientos sociales y morales ${ }^{62}$. Ushuaia - el confín del mundo-, la prisión -la «Siberia argentina»-, proporcionaba en este aspecto un ángulo fructífero de estudio. Los trabajadores de la urbanización eran sometidos al mismo tiempo a la observación científica. En un contexto de aislamiento, esta población - cautiva, controlada, uniforme en su esencia criminal-, sumi-

60. En los archivos de la oficina de identificación antropométrica de la Policía de la Capital se acumulaban «los datos de identificación correspondientes á un gran número de delincuentes». En la memoria del año correspondiente a 1894, se puede leer: «Por medio de las reproducciones fotográficas, de las mediciones ideadas según el sistema del Dr. Bertillon y la perfecta combinación de los datos sacados para cada identificación queda asegurada la comprobación de los delincuentes identificados y en cualquier circunstancia la expedición de informes se efectúa de la manera más rápida y sencilla». Memoria del Ministro del Interior ante el Congreso Nacional correspondiente al año de 1894. Tomos 1 y 2. Buenos Aires: Imprenta de La Tribuna; 1895, p. 343.

61. Urías Horcacitas, Beatriz. Indígena y criminal. Interpretaciones del derecho y la antropología en México, 1871-1921. México: Universidad Iberoamericana-Departamento de Historia; 2000, p. 10. Extendemos la noción de grupo étnico hacia el resto de los colectivos étnico-políticos que habitan el territorio nacional.

62. Una de las formas utilizadas para mostrar las desviaciones fueron las fotografías de frente y perfil adoptadas por los sistemas policiales y judiciales oficiales como garantía de una perfecta identificación. Identificación que se realizaba a partir de «la adquisición de datos acerca de las anomalías craneales, fisonómicas y de la sensibilidad táctil». Penhos, Marta. Frente y perfil. Una indagación acerca de la fotografía en las prácticas antropológicas y criminológicas en Argentina a fines del siglo XIX y principios del siglo XX. In: Arte y antropología en la Argentina. Argentina: Fundación Espigas; 2005, p. 17-62. Estos análisis fueron aplicados tanto a inmigrantes considerados peligrosos como a indígenas. Sin embargo, esta morfología nace para retratar en primera instancia al indio, y con posterioridad al inmigrante-delincuentecriminal. V. Lehmann-Nitsche, Robert; De Madrid, Samuel. Informe pericial acerca del estado psíquico y somático del procesado Juan B. Passo. Anales del Círculo Médico Argentino. 1900; 23 (2): 4-47. 
nistraba al científico un corpus siempre disponible de información para contrastar sus hipótesis.

\section{Conclusiones}

La nación argentina, como el resto de las naciones latinoamericanas, enfrentó la decadencia del mundo urbano, atribuida a diferentes prototipos de indeseables. La visibilidad de estos otros políticos a lo largo y ancho del país (indígenas, inmigrantes, anarquistas), permitía, a fines del siglo XIX y principios del siglo XX, «parcializar a la sociedad e identificar sus componentes, definiendo y clasificando sobre todo a aquellos que se salían de la norma, y alcanzar sobre ellos una visibilidad sin fisuras, sacando máximo provecho de los instrumentos de observación y registro» ${ }^{63}$.

Hemos indagado en este escrito dos ejes, ambos en profunda consonancia con las necesidades científicas y los científicos del momento. Tanto en el estudio pormenorizado de los indígenas fueguinos $-\mathrm{y}$ su inminente e inevitable extinción - como en el practicado a los reincidentes y criminales del penal de Ushuaia, se pusieron en práctica modernos sistemas de control, experimentación, normalización y objetivación en la tipificación de los otros internos ${ }^{64}$.

El biopoder; esto es, la articulación que se da entre los procedimientos propios de la biopolítica y los procedimientos propios del poder disciplinar, es interpretado así desde dos ópticas. En primer lugar, como parte de un accionar genocida hacia los pueblos originarios (dejar morir a los fueguinos). La antropometría y el control de los cuerpos por medio de las fotografías, entre otras disciplinas o métodos, permitieron justificar la inferioridad biológica de dichos grupos humanos y su exclusión de la sociedad nacional.

En segundo lugar, la crisis demográfica de Tierra del Fuego y la necesidad de poblar la isla coadyuvó en la búsqueda de los sujetos del progreso (hacer

63. Penhos, n. 62. Conceptos tomados de Foucault, Michel. Vigilar y castigar. Nacimiento de la prisión. México D.F.: FCE; 1987.

64. La integración o exclusión de los grupos sociales dentro la sociedad argentina: inmigrantes/ gringos; indios/población nativa suma, a la referencia étnico-racial, la vinculada a la éticomoral. Así como la representación del inmigrante fue modificada en el centenario por ser considerada un foco de peligrosidad, fue también en última instancia el discurso médico el que determinó el deber ser del ciudadano. Scarzanella, Eugenia. Ni gringos ni indios. Inmigración, criminalidad y racismo en Argentina. 1890-1940. Buenos Aires: UNQ; 2002. 
vivir al delincuente). Ushuaia se convertirá, con la creación del principal penal de la Argentina, y paralelamente al disciplinamiento de la cuestión indígena, en una suerte de contracara de la imagen de normalidad de la metrópolis; el sitio por antonomasia para encerrar la anormalidad que se buscaba erradicar de Buenos Aires y que estaba generando la decadencia del mundo urbano aludida y denunciada para la época. Anormalidad que, sin embargo, podría en este caso regenerarse o corregirse por medio del trabajo; algo sumamente cuestionado por las ideas criminológicas del momento. La idea de coyuntura se instala con fuerza. La regeneración iría de la mano con una necesidad: la colonización y el ejercicio de la soberanía nacional en la isla.

La ciencia desplegará -el gabinete antropométrico es ejemplo de ello- sus modernos mecanismos de poder y control. Marco propicio de estudio para la formulación de tesis científicas sobre la peligrosidad social, la cárcel de Ushuaia se constituyó como panóptico; «un brillante faro de modernidad punitiva en el fin del mundo» y no simplemente un lugar para deshacerse de los incorregibles ${ }^{65}$.

65. Caimari, n. 44, p. 67. Es interesante observar las similitudes que se observan entre Australia y Tierra del Fuego, en función de la colonización llevada a cabo por los presos y la idea de panóptico. En ambos casos, «el convicto, en su exilio australiano, se convertiría en una propiedad rentable, un esclavo puesto al servicio de todos. Su cuerpo [...] Pasaba a ser un bien social, objeto de una apropiación colectiva y útil». Y por otro lado, la cárcel encarnaría el panóptico soñado, «una máquina que moliera a los malhechores y los volviera honrados». Pimentel, n. 38, p. 33-34. 


\section{Tierra del Fuego: the scientific-political construction of exclusion and counter-image of the ideal city dweller}

Gabriela Nacach .........................................

1.-Bring the delinquent to life, let the Indians die. 2.-State and Salesian agencies in the colonization of the Indian. 3.-Bioanthropological colonization. 3.1.-Taxonomy and register. 3.2.-Paradigm of extinction. 4.- Ushuaia Prison: counterimage of the citizen or the other face of the nation's ideal of normality? 4.1.-Penal colonization. 4.1.1.-The criminals: subjects of the territory's progress. 4.1.2.-An office for control and observation. 5.-Conclusions.

ABSTRACT: Due to its late incorporation into the national State, the social, economic and political setting of the Argentine province Tierra del Fuego differed from that of the rest of the national territory. In the construction of dependent otherness, objectifications and representations were imposed by state-related and non-state-related institutions, among other agencies. In this context, the Salesian mission of La Candelaria and Ushuaia's Jail for recidivists stand out as spaces in which biopolitics was concretised. The native population and criminals in Tierra del Fuego were those to be subjugated. The thesis of the extinction of the Indian and the simultaneous exaltation of the criminal as the subject of progress identified the scientific and political mechanisms by which the exclusion of certain social groups (Tierra del Fuego's indigenous population) and the inclusion of others (criminals) were regulated. 